\title{
MATURAÇÃO E SECAGEM DE SEMENTES DE Peltophorum dubium (Spreng.) Taubert (CANAFÍSTULA) ${ }^{1}$
}

\author{
João Nakagawa², Edson Seizo Mori ${ }^{3}$, Cleber da Silva Pinto ${ }^{3}$, Kairo Henrique Pereira Fernandes ${ }^{3}$, \\ Maurício Shoji Seki ${ }^{3}$ e Rogério Augusto Meneghetti ${ }^{3}$
}

\begin{abstract}
RESUMO - O trabalho foi desenvolvido em Botucatu, SP, e teve por objetivo determinar o momento de ocorrência do máximo potencial de germinação durante a maturação das sementes de canafístula, relacionando-a com a secagem dos frutos. Cinco árvores, em final de floração, tiveram 15 inflorescências etiquetadas em 06/02/ 2002. As colheitas, realizadas semanalmente, foram iniciadas na quinta semana após a etiquetagem (35 DAE) e finalizaram quando ocorreu o início da dispersão dos frutos (98 DAE), totalizando 10 colheitas. Os frutos das cinco plantas foram colhidos e avaliados separadamente. Em cada colheita, os frutos foram divididos em duas porções: uma teve as sementes extraídas (sementes frescas), e a outra foi posta para secar em ambiente natural de laboratório para, então, se extraírem as sementes (sementes secas). Determinaram-se o teor de água e a massa seca de 100 sementes frescas e 100 secas. Os testes de germinação das sementes, frescas e secas, foram realizados com e sem escarificação. O delineamento experimental utilizado foi o de blocos casualizados, considerando-se a árvore e o bloco. A maior capacidade germinativa das sementes foi atingida após a ocorrência do máximo acúmulo de massa. O máximo potencial de germinação, detectado nas sementes escarificadas, foi observado no início da dispersão, quando predominavam sementes duras. A maturação, a germinação e a instalação da dormência em semente imatura foram antecipadas com a sua secagem no interior do fruto separado da planta-mãe.
\end{abstract}

Palavras-chave: Peltophorum dubium, Germinação e Maturação de sementes.

\section{MATURATION AND DRYING OF Peltophorum dubium (Spreng.) Taubert (HORSEBUSH) SEEDS}

\begin{abstract}
SUMMARY - This study was carried out in Botucatu City, São Paulo State, Brazil with the objective of determining the time of maximum germination during maturation of horsebush seeds, in relation to fruit drying. Five trees, at the end of flowering had 15 inflorescences labeled on 06/02/2002. Weekly harvests were carried out from the fifth week after the inflorescences were labeled (35 DAL-days after labeling) and ended at the beginning of fruit dispersal (98 DAL), totalizing ten harvests. Fruits of five trees were harvested and evaluated separately. For each harvest, fruits were split in two lots: one lot had the seeds extracted for germination (fresh seeds) and the other was dried on room temperature before seed extraction (dry seeds). Water content and dry matter weight of 100 seeds were evaluated on both fresh and dry seeds. Germination tests of fresh and dry seeds were performed with and without scarification. The experiment was arranged in a complete randomized block design, considering a tree as a block. The highest seed germination capacity was reached after the maximum mass accumulation. Maximum germination, was found in scarified seeds at the beginning of seed dispersal, when hard seeds predominated. Maturation, germination, and induction of seed dormancy in immature seeds were anticipated with they dryed inside the fruits separated from the mother tree.
\end{abstract}

Keywords: Peltophorum dubium, Germination and Seed Maturation.

\footnotetext{
${ }^{1}$ Recebido em 13.02.2008 e aceito para publicação em 14.10.2009.

${ }^{2}$ Universidade Estadual Paulista Júlio de Mesquita Filho, Faculdade de Ciências Agronômicas de Botucatu, Departamento de Produção Vegetal - Botucatu, SP - Brasil. E-mail: <khpfernandes@fca.unesp.br>.

${ }^{3}$ Faculdade de Ciências Agronômicas - UNESP - Botucatu, SP - Brasil. E-mail: <kairofernandes@yahoo.com.br>.
} 


\section{INTRODUÇÃO}

A canafístula Peltophorum dubium (Spreng.) Taub. (Fabaceae - Caesalpinioideae) é uma espécie frequente em todo o domínio da Floresta Estacional Semidecidual, abundante em formações secundárias, mas com poucos indivíduos em floresta primária ocupando o estrato dominante do dossel (DURIGAN et al., 1997). Sua madeira é empregada na construção civil, marcenaria, tanoaria, carrocerias, dormentes etc. A árvore, de crescimento rápido, muito rústica e heliófila, é recomendada para reflorestamentos mistos de áreas degradadas, para paisagismo em geral, arborização de parques, praças e rodovias (LORENZI, 1992; MARCHIORI, 1997).

O processo reprodutivo inicia-se entre 8 e 12 anos, florescendo de dezembro a fevereiro, com a maturação das sementes de abril a junho. A dispersão dos frutos é feita lentamente pelo vento, mas os frutos maduros permanecem na árvore por longo tempo (DURIGAN et al., 1997).

O fruto é um legume samaroide, seco, indeiscente; apresenta de uma a duas sementes, com predominância dos monospérmicos (DONADIO e DEMATTÊ, 2000); quando maduro é de coloração marrom-escura (FIGLIOLIA, 1995). As sementes são estenospérmicas, oblongas, de coloração castanho-esverdeado-clara, com testa relativamente espessa, de consistência córnea quando secas (DONADIO e DEMATTÊ, 2000). Essas características do tegumento proporcionam a dormência apresentada pelas sementes, comum às espécies da família Fabaceae (BIANCHETTI e RAMOS, 1982; PEREZ et al., 1999), que é a dificuldade de embebição devido à impermeabilidade do tegumento das sementes à água, resultando sementes duras (BRASIL, 1992).

Os frutos maduros, colhidos das árvores, podem ser semeados diretamente, porém, como há possibilidade de formarem mudas defeituosas, deve-se preferir extrair as sementes dos frutos (LORENZI, 1992). Assim, a utilização das sementes beneficiadas e que sofreram o processo de superação de dormência apresenta melhores resultados de germinação em laboratório e no viveiro do que o uso dos frutos (FIGLIOLIA e SILVA, 1982).

A dormência instala-se durante a fase de desenvolvimento e, ou, maturação, o que resulta sementes dormentes na dispersão. Esse fenômeno dificulta o estudo de maturação, o trabalho dos analistas e a formação de mudas pelos viveiristas, porque a avaliação da capacidade de germinação é prejudicada. Há, em razão disso, a sugestão de se realizar a colheita seguida da semeadura imediata de grande quantidade de sementes imaturas, para aquelas espécies florestais cujas sementes maduras são dormentes e as imaturas apresentam certo percentual de germinação (EDWARDS, 1980; PIÑARODRIGUES E AGUIAR, 1993).

As sementes, com dormência causada pelo tegumento impermeável à água, são capazes de embeber e germinar quando maduras fisiologicamente, mas devem ser colhidas antes de iniciarem a dessecação (CARDOSO, 2004), pois essa impermeabilidade se desenvolve no período em que ocorre rápida perda de água e se estabelece, segundo a espécie considerada, com teores de 2 a $21 \%$ de água (BASKIN e BASKIN, 1998).

A colheita de frutos imaturos, seguida da secagem lenta, promove a maturação das sementes, mesmo separados da planta, mas antecipa a ocorrência e aumenta o número de sementes duras de mucuna-preta (NAKAGAWA et al., 2005), mostrando o efeito da secagem na instalação da impermeabilidade do tegumento.

Tendo em vista esses aspectos sobre maturação e dormência de sementes, este trabalho teve como objetivo determinar o momento de ocorrência do máximo potencial de germinação durante a maturação das sementes de canafístula, relacionado-as com a secagem dos frutos.

\section{MATERIAL E MÉTODOS}

O trabalho teve início com a etiquetagem de 15 inflorescências em cada uma das cinco árvores escolhidas de canafístula (Peltophorum dubium (Spreng.) Taubert), que apresentavam frutificação intensa. As etiquetas foram colocadas nas inflorescências em fase final de florescimento. Os indivíduos marcados estão localizados no Campus de Botucatu/UNESP, no Distrito de Rubião Junior, em Botucatu, SP.

As colheitas dos frutos, em intervalos semanais, foram iniciadas na quinta semana após a etiquetagem (35 DAE) e finalizadas na décima quarta semana (98 DAE), quando os frutos começaram a dispersar. Foram realizadas 10 colheitas no total. Os frutos foram mantidos separados por indivíduo, assim como as sementes, durante todos os procedimentos e avaliações. As sementes de cada indivíduo constituíram as repetições das características avaliadas. Os frutos foram divididos 
em duas porções e, a primeira teve suas sementes extraídas ainda úmidas (sementes frescas) para as avaliações; a segunda foi colocada em bandejas e mantida em ambiente natural de laboratório até completarem a secagem para, então, se realizar a extração das sementes (sementes secas) para as determinações.

Nas sementes frescas foram determinados o teor de água e a massa seca de 100 sementes em todas as 10 colheitas, enquanto nas sementes secas essas determinações foram feitas da $4^{\mathrm{a}}$ à $8^{\mathrm{a}}$ colheita, por falta de material (sementes) nas repetições. As sementes frescas e as secas foram submetidas ao teste de germinação, a partir da primeira colheita. Adeterminação do teor de água foi realizada empregando-se cinco repetições de 20 sementes, pelo método da estufa a $105^{\circ}+/-3^{\circ} \mathrm{C}$ por $24 \mathrm{~h}$ (BRASIL, 1992). A massa seca de 100 sementes foi calculada utilizando-se os valores de massa seca das 20 sementes obtidos na determinação do teor de água.

As sementes frescas e as secas de cada colheita foram submetidas ao teste de germinação, com ou sem escarificação. A escarificação foi realizada, manualmente, na extremidade oposta à hilar afinada da semente, com lixa $n^{\circ} 100$ (SANTOS et al., 2004). O teste de germinação foi realizado com cinco repetições de 20 sementes, semeadas em duas folhas de papel mata-borrão (SP), previamente umedecidas com água (2,5 vezes o peso do substrato) e colocadas em caixa plástica transparente (gerbox) com tampa. O teste foi conduzido a $30^{\circ} \mathrm{C}$ (OLIVEIRA et al., 1989), com fotoperíodo de $8 \mathrm{~h}$ de luz e $16 \mathrm{~h}$ de escuro. As contagens foram feitas aos 7, 14, 21 e 28 dias, com avaliações das plântulas e das sementes de acordo com os critérios das Regras para Análise de Sementes (BRASIL, 1992). Os resultados foram expressos em número de plântulas normais (germinação) e anormais, sementes duras e mortas.

Todos os dados foram submetidos à análise estatística, em delineamento de blocos ao acaso, considerando-se as cinco árvores como os blocos. O teor de água e a massa seca de 100 sementes foram analisados levando-se em conta as épocas de colheita como tratamentos. Os dados do teste de germinação foram analisados considerando-se como tratamentos, épocas de colheita e sementes com e sem escarificação, em esquema fatorial. As análises foram realizadas separadamente quanto aos dados de avaliação das sementes frescas e das sementes secas. Foi realizada também a comparação dos resultados de massa seca de 100 sementes e dos dados do teste de germinação entre sementes frescas e secas, em esquema fatorial, considerando, épocas de colheita x com e sem secagem das sementes. Os dados em porcentagem foram transformados em arco-seno $\sqrt{\% / 100}$ e os em número em $\sqrt{x+0,5}$, para as análises estatísticas (GOMES, 2000). As comparações entre as médias foram feitas pelo teste de Tukey ( $5 \%$ ). As médias apresentadas nas tabelas são dos dados originais.

\section{RESULTADOS E DISCUSSÃO}

O teor de água das sementes frescas diminuiu gradativamente da primeira (35 DAE) à quinta colheita (63 DAE); da sexta semana em diante, os decréscimos foram maiores, em que entre a penúltima e a última colheita se observou a perda mais rápida (Tabela 1). Concomitantemente aos decréscimos do teor de água, ocorreu o acúmulo da massa seca de forma crescente da primeira à sexta colheita (70 DAE), para, a partir da qual, manter valores semelhantes (Tabela 1). Pode-se inferir por esses resultados que as sementes, por apresentarem o máximo acúmulo de massa, teriam atingido a maturidade aos 70 DAE, pois o que aconteceu a seguir foi a dessecação, favorecendo a dispersão, cujo início foi verificado na última colheita (98 DAF), quando o teor de água era de $11,0 \%$.

As sementes secas, extraídas dos frutos após a secagem, mostraram semelhanças de massa seca no período dos 56 aos 84 DAE (Tabela 1). Na comparação das massas secas entre sementes frescas e secas, verificaram-se diferenças nas colheitas aos 56, 63 e 77 DAE, com valores maiores para as sementes secas (Tabela 1), indicando que durante a secagem dos frutos, depois de colhidos, houve translocação de nutrientes dos frutos para as sementes, mesmo estando separados da planta. Fato semelhante foi observado em sementes de mucuna-preta, uma leguminosa forrageira também usada para adubação verde (NAKAGAWA et al., 2005). Pelos resultados da massa seca das sementes que sofreram secagem nos frutos, o máximo da massa foi atingido na colheita aos 77 DAE (Tabela 1), uma semana após as das sementes frescas, o que leva a deduzir que aos 70 DAE as sementes não haviam alcançado a maturidade, como comentado anteriormente.

R. Árvore, Viçosa-MG, v.34, n.1, p.49-56, 2010 
Tabela 1 - Médias de teor de água e massa seca de 100 sementes de canafístula obtidas das sementes frescas e as sementes secas nos frutos em diferentes épocas de colheita, definidas em dias após a etiquetagem (DAE).

Table 1 - Means of water content and dry matter weight of 100 horsebush seeds obtained from both fresh and seeds dried inside the fruits at different harvest times, (days after labeling - DAL).

\begin{tabular}{|c|c|c|c|c|c|c|}
\hline \multirow{2}{*}{$\begin{array}{c}\text { Tratamentos } \\
\text { Colheita (DAE) }{ }^{1}\end{array}$} & \multicolumn{2}{|c|}{ Sementes Frescas } & \multicolumn{2}{|c|}{ Sementes Secas } & \multicolumn{2}{|c|}{ Massa Seca (g) } \\
\hline & $\begin{array}{l}\text { Teor de } \\
\text { Água }(\%)\end{array}$ & $\begin{array}{c}\text { Massa Seca } \\
\text { (g) }\end{array}$ & $\begin{array}{l}\text { Teor de } \\
\text { Água }(\%)\end{array}$ & $\begin{array}{c}\text { Massa Seca } \\
(\mathrm{g})\end{array}$ & $\begin{array}{c}\text { Sementes } \\
\text { Frescas }\end{array}$ & $\begin{array}{c}\text { Sementes } \\
\text { Secas }\end{array}$ \\
\hline 35 & $89,7 \mathrm{a}^{(2)}$ & $0,094 \mathrm{c}$ & - & - & - & - \\
\hline 42 & $86,1 \mathrm{ab}$ & $0,754 \mathrm{bc}$ & - & - & - & - \\
\hline 49 & $84,1 \mathrm{ab}$ & $0,953 \mathrm{bc}$ & - & - & - & - \\
\hline 56 & $85,4 \mathrm{ab}$ & $0,977 \mathrm{bc}$ & $5,9 \mathrm{~b}$ & $2,723 \mathrm{a}$ & $0,977 b^{\text {B }}$ & $2,723 b^{A}$ \\
\hline 63 & $79,9 \mathrm{~b}$ & $1,439 \mathrm{~b}$ & $6,7 \mathrm{~b}$ & 3,543 a & $1,439 b^{\mathrm{B}}$ & $3,543 \mathrm{ab}^{\mathrm{A}}$ \\
\hline 70 & $69,1 \mathrm{c}$ & 3,145 a & $8,3 \mathrm{a}$ & 3,122 a & $3,145 \mathrm{a}^{\mathrm{A}}$ & $3,122 a b^{A}$ \\
\hline 77 & $64,0 \mathrm{~cd}$ & $2,628 \mathrm{a}$ & $8,1 \mathrm{a}$ & 3,761 a & $2,628 \mathrm{a}^{\mathrm{B}}$ & $3,761 \mathrm{a}^{\mathrm{A}}$ \\
\hline 84 & $55,4 \mathrm{de}$ & 3,564 a & $6,7 \mathrm{~b}$ & 3,380 a & $3,564 \mathrm{a}^{\mathrm{A}}$ & $3,380 \mathrm{ab}^{\mathrm{A}}$ \\
\hline 91 & $45,5 \mathrm{e}$ & $3,190 \mathrm{a}$ & (3) & (3) & - & - \\
\hline 98 & $11,0 \mathrm{f}$ & 3,682 a & (3) & (3) & - & - \\
\hline C.V. $(\%)$ & 5,04 & 25,29 & 4,39 & 20,12 & & \\
\hline
\end{tabular}

(1) Dias após a etiquetagem; etiquetagem das inflorescências em final de florescimento.

(2) Médias seguidas da mesma letra, minúscula na coluna e maiúscula na linha, não diferem entre si, pelo teste de Tukey a $5 \%$.

(3) Não determinado por falta de material nas repetições.

Tabela 2 - Médias de germinação, plântulas anormais, sementes mortas e sementes duras de canafístula obtidas de sementes frescas, sem e com escarificação (S/ESC e C/ESC), originárias de diferentes épocas de colheita definidas em dias após a etiquetagem $(\mathrm{DAE})\left(\mathrm{n}^{\circ}=20\right.$ sementes por repetição).

Table 2 - Means of germination, abnormal seedlings, dead seeds, and hard seeds of horsebush obtained for fresh seeds, with and without scarification, at different harvest times (days after labeling - DAL). $\left(n^{o}=20\right.$ seeds per replication).

\begin{tabular}{|c|c|c|c|c|c|c|}
\hline \multirow[t]{2}{*}{$\begin{array}{c}\text { Tratamentos } \\
\text { Colheita/Escarificação }\end{array}$} & \multicolumn{2}{|c|}{$\begin{array}{l}\text { Germinação } \\
\left(\mathrm{n}^{\circ}\right)\end{array}$} & \multirow[t]{2}{*}{$\begin{array}{c}\text { Plântulas } \\
\text { Anormais }\left(\mathrm{n}^{\circ}\right)\end{array}$} & \multirow[t]{2}{*}{$\begin{array}{l}\text { Sementes } \\
\text { Mortas }\left(\mathrm{n}^{\circ}\right)\end{array}$} & \multicolumn{2}{|c|}{$\begin{array}{l}\text { Sementes } \\
\text { Duras }\left(n^{\circ}\right)\end{array}$} \\
\hline & S/ESC & $\mathrm{C} / \mathrm{ESC}$ & & & S/ESC & C/ESC \\
\hline \multicolumn{7}{|l|}{$(\mathrm{DAE})^{1}$} \\
\hline 77 & $0,80 \mathrm{~b}^{\mathrm{A}(2)}$ & $0,40 \mathrm{c}^{\mathrm{A}}$ & $1,90 \mathrm{ab}$ & $17,50 \mathrm{a}$ & $0,00 \mathrm{c}^{\mathrm{A}}$ & $0,00 \mathrm{~b}^{A}$ \\
\hline 84 & $2,80 \mathrm{~b}^{\mathrm{B}}$ & $9,80 \mathrm{~b}^{\mathrm{A}}$ & $4,00 \mathrm{a}$ & $2,70 \mathrm{~b}$ & $11,20 \mathrm{ab}^{\mathrm{A}}$ & $2,80 \mathrm{a}^{\mathrm{H}}$ \\
\hline 91 & $8,40 \mathrm{a}^{\mathrm{A}}$ & $13,00 \mathrm{ab}^{\mathrm{A}}$ & $3,00 \mathrm{ab}$ & $2,50 \mathrm{~b}$ & $7,00 \mathrm{~b}^{\mathrm{A}}$ & $0,60 a b^{1}$ \\
\hline 98 & $1,80 \mathrm{~b}^{\mathrm{B}}$ & $17,80 \mathrm{a}^{\mathrm{A}}$ & $1,10 \mathrm{~b}$ & $0,60 \mathrm{~b}$ & $16,80 \mathrm{a}^{\mathrm{A}}$ & $0,20 \mathrm{~b}^{\mathrm{F}}$ \\
\hline $\mathrm{S} / \mathrm{ESC}$ & - & - & $2,35 \mathrm{~A}$ & $5,45 \mathrm{~A}$ & - & - \\
\hline $\mathrm{C} / \mathrm{ESC}$ & - & - & $2,65 \mathrm{~A}$ & $6,20 \mathrm{~A}$ & & - \\
\hline C.V. (\%) & \multicolumn{2}{|c|}{23,15} & 60,89 & 27,63 & \multicolumn{2}{|c|}{27,19} \\
\hline
\end{tabular}

(1) Dias após a etiquetagem; etiquetagem das inflorescências em final de florescimento.

(2) Médias seguidas da mesma letra, minúscula para colheita e maiúscula para escarificação, não diferem entre si, pelo teste de Tukey a $5 \%$.

As sementes frescas das colheitas iniciais submetidas ao teste de germinação originaram somente sementes mortas; nas colhidas aos 77 DAE ocorreu a germinação, mas ainda predominaram as sementes mortas (Tabela 2). Nas colheitas seguintes, com decréscimos mais acentuados do teor de água (Tabela 1), houve aumentos das sementes duras e da germinação das sementes escarificadas e diminuição das sementes mortas e das plântulas anormais, mostrando melhoria do potencial germinativo (Tabela 2).

Pelos dados de massa seca de 100 sementes (Tabela 1), aos 70 DAE as sementes já apresentavam o máximo de acúmulo de massa e elevado teor de água, porém não mostravam capacidade de germinação. Isso pode 
ser indicativo de que não haviam atingido a maturidade fisiológica ou que, para a canafístula, é importante a secagem prévia das sementes para ocorrer o processo de germinação, pré-requisito para algumas espécies (BASKIN e BASKIN, 1998).

A eficiência da escarificação e a sua necessidade em canafístula (OLIVEIRA et al., 2003) foram evidenciadas pelos resultados de sementes duras e de germinação das sementes escarificadas e não escarificadas (Tabela 2), mesmo em colheitas em que o teor de água das sementes frescas era ainda elevado (Tabela 1), porém foi mais notória na última colheita, quando o teor era de $11,0 \%$, ocasião em que, com a secagem, a impermeabilidade do tegumento à água instalou-se na maioria das sementes (BASKIN e BASKIN, 1998).

Nas sementes secas, a germinação ocorreu aos 56 DAE (Tabela 3), portanto três semanas antes das sementes frescas (Tabela 2). Essa antecipação da germinação pode ser atribuída ao processo de secagem lenta das sementes nos frutos que promoveram a maturação, detectada pelo acúmulo de massa (Tabela 1), e também em função da desidratação das sementes (Tabela 1) que deve ter estimulado o processo de germinação (BASKIN e BASKIN, 1998). A desidratação, natural ou imposta permanentemente, faz que a semente mude o programa de expressão de genes de maturação para o processo de germinação, acompanhado do redirecionamento do metabolismo para germinação e crescimento (KERMODE, 1995). Com o avançar da maturação, houve acréscimos da germinação nas sementes escarificadas até a colheita aos 77 DAE, seguidos de valores semelhantes nas colheitas seguintes, enquanto o número de sementes mortas diminuiu a partir daquela colheita (Tabela 3). Nas sementes não escarificadas não houve diferenças entre colheitas para germinação, plântulas anormais, sementes mortas e duras. Com a escarificação das sementes secas, o comportamento da maturação das sementes quanto à viabilidade pode ser mais bem avaliado, pois a dormência por impermeabilidade do tegumento restringe a germinação na maturidade (SIDHU e CAVERS, 1977; CHAVES e KAGEYAMA, 1980). Em sementes maduras e secas de canafístula, a superação dessa dormência é importante para se avaliar a germinação (PEREZ et al., 1999; OLIVEIRA et al., 2003; 2008).

Tabela 3 - Médias de germinação, plântulas anormais, sementes mortas e sementes duras de canafístula obtidas de sementes secas nos frutos, sem e com escarificação (S/ESC e C/ESC), originárias de diferentes épocas de colheita definidas em dias após a etiquetagem (DAE) $\left(\mathrm{n}^{\circ}=20\right.$ sementes por repetição).

Table 3 - Means of germination, abnormal seedlings, dead seeds, and hard seeds of horsebush obtained for seeds dried inside fruits, with and without scarification, at different harvest times (days after labeling $-D A L) .\left(n^{\circ}=20\right.$ seeds per replication).

\begin{tabular}{|c|c|c|c|c|c|c|}
\hline \multirow[t]{2}{*}{$\begin{array}{c}\text { Tratamentos } \\
\text { Colheita/Escarificação }\end{array}$} & \multicolumn{2}{|c|}{$\begin{array}{l}\text { Germinação } \\
\left(n^{\circ}\right)\end{array}$} & \multirow[t]{2}{*}{$\begin{array}{c}\text { Plântulas } \\
\text { Anormais }\left(n^{\circ}\right)\end{array}$} & \multicolumn{2}{|c|}{$\begin{array}{c}\text { Sementes } \\
\text { Mortas }\left(n^{\circ}\right)\end{array}$} & \multirow[t]{2}{*}{$\begin{array}{l}\text { Sementes } \\
\text { Duras }\left(\mathrm{n}^{\circ}\right)\end{array}$} \\
\hline & $\mathrm{S} / \mathrm{ESC}$ & C/ESC & & $\mathrm{S} / \mathrm{ESC}$ & $\mathrm{C} / \mathrm{ESC}$ & \\
\hline \multicolumn{7}{|l|}{$(\mathrm{DAE})^{1}$} \\
\hline 56 & $6,60 \mathrm{a}^{\mathrm{A}(2)}$ & $7,00 \mathrm{c}^{\mathrm{A}}$ & $0,70 \mathrm{a}$ & $6,80 \mathrm{a}^{\mathrm{A}}$ & $8,20 \mathrm{a}^{\mathrm{A}}$ & 5,0 a \\
\hline 63 & $7,00 \mathrm{a}^{\mathrm{A}}$ & $11,20 \mathrm{abc}^{\mathrm{A}}$ & $1,20 \mathrm{a}$ & $4,60 \mathrm{a}^{\mathrm{A}}$ & $7,40 \mathrm{ab}^{\mathrm{A}}$ & $3,7 \mathrm{a}$ \\
\hline 70 & $7,60 \mathrm{a}^{\mathrm{A}}$ & $9,40 \mathrm{bc}^{\mathrm{A}}$ & $1,60 \mathrm{a}$ & $5,40 \mathrm{a}^{\mathrm{A}}$ & $8,00 \mathrm{a}^{\mathrm{A}}$ & $3,2 \mathrm{a}$ \\
\hline 77 & $4,40 \mathrm{a}^{\mathrm{B}}$ & $17,00 \mathrm{ab}^{\mathrm{A}}$ & $1,00 \mathrm{a}$ & $7,20 \mathrm{a}^{\mathrm{A}}$ & $1,00 b^{B}$ & $4,2 \mathrm{a}$ \\
\hline 84 & $2,60 \mathrm{a}^{\mathrm{B}}$ & $17,80 \mathrm{a}^{\mathrm{A}}$ & $1,00 \mathrm{a}$ & $9,60 \mathrm{a}^{\mathrm{A}}$ & $0,60 b^{B}$ & $3,7 \mathrm{a}$ \\
\hline 91 & $6,40 a^{B}$ & $18,00 \mathrm{a}^{\mathrm{A}}$ & $0,60 \mathrm{a}$ & $5,80 \mathrm{a}^{\mathrm{A}}$ & $0,80 b^{B}$ & 3,9 a \\
\hline 98 & $6,60 \mathrm{a}^{\mathrm{B}}$ & $17,40 \mathrm{ab}^{\mathrm{A}}$ & $0,60 \mathrm{a}$ & $5,20 \mathrm{a}^{\mathrm{A}}$ & $1,00 \mathrm{~b}^{\mathrm{B}}$ & $4,3 \mathrm{a}$ \\
\hline S/ESC & - & - & $1,11 \mathrm{~A}$ & - & - & $6,63 \mathrm{~A}$ \\
\hline C/ESC & - & - & $0,80 \mathrm{~A}$ & - & - & $1,37 \mathrm{~B}$ \\
\hline C.V. $(\%)$ & \multicolumn{2}{|c|}{23,15} & 60,89 & \multicolumn{2}{|c|}{27,63} & 27,19 \\
\hline
\end{tabular}

\footnotetext{
(1) Dias após a etiquetagem; etiquetagem das inflorescências em final de florescimento.

(2) Médias seguidas da mesma letra, minúscula para colheita e maiúscula para escarificação, não diferem entre si, pelo teste de Tukey a $5 \%$.
} 
Tabela 4 - Médias de germinação, plântulas anormais, sementes mortas e sementes duras de canafístula obtidas para sementes frescas (S/SEC) e sementes secas nos frutos (C/SEC), sem escarificação, originárias de diferentes épocas de colheita definidas em dias após a etiquetagem (DAE) $\left(\mathrm{n}^{\circ}=20\right.$ sementes por repetição).

Table 4-Means of germination, abnormal seedlings, dead seeds, and hard seeds of horsebush obtained for fresh seeds (without drying) and seeds dried inside the fruits (artificial drying), both without scarification, at different harvest times (days after labeling - DAL). ( $n^{o}=20$ seeds per replication).

\begin{tabular}{|c|c|c|c|c|c|c|c|}
\hline \multirow[t]{2}{*}{$\begin{array}{c}\text { Tratamentos } \\
\text { Colheita/Escarificação }\end{array}$} & \multicolumn{2}{|c|}{$\begin{array}{l}\text { Germinação } \\
\left(n^{\circ}\right)\end{array}$} & \multirow[t]{2}{*}{$\begin{array}{c}\text { Plântulas } \\
\text { Anormais }\left(n^{\circ}\right)\end{array}$} & \multicolumn{2}{|c|}{$\begin{array}{c}\text { Sementes } \\
\text { Mortas }\left(n^{\circ}\right)\end{array}$} & \multicolumn{2}{|c|}{$\begin{array}{l}\text { Sementes } \\
\text { Duras }\left(n^{\circ}\right)\end{array}$} \\
\hline & $\mathrm{S} / \mathrm{ESC}$ & $\mathrm{C} / \mathrm{ESC}$ & & $\mathrm{S} / \mathrm{ESC}$ & $\mathrm{C} / \mathrm{ESC}$ & $\mathrm{S} / \mathrm{ESC}$ & $\mathrm{C} / \mathrm{ESC}$ \\
\hline \multicolumn{8}{|l|}{$(\mathrm{DAE})^{1}$} \\
\hline 77 & $0,80 \mathrm{~b}^{\mathrm{B}(2)}$ & $4,40 a b^{A}$ & $2,10 \mathrm{a}$ & $16,20 \mathrm{a}^{\mathrm{A}}$ & $7,20 \mathrm{a}^{\mathrm{B}}$ & $0,00 \mathrm{c}^{\mathrm{B}}$ & $7,20 \mathrm{a}^{\mathrm{A}}$ \\
\hline 84 & $2,80 \mathrm{~b}^{\mathrm{A}}$ & $2,60 \mathrm{~b}^{\mathrm{A}}$ & $2,10 \mathrm{a}$ & $3,20 b^{B}$ & $9,60 \mathrm{a}^{\mathrm{A}}$ & $11,20 \mathrm{ab}^{\mathrm{A}}$ & $6,40 \mathrm{a}^{\mathrm{A}}$ \\
\hline 91 & $8,40 \mathrm{a}^{\mathrm{A}}$ & $6,40 \mathrm{a}^{\mathrm{A}}$ & $1,90 \mathrm{a}$ & $1,80 \mathrm{~b}^{\mathrm{A}}$ & $5,80 \mathrm{a}^{\mathrm{A}}$ & $7,00 \mathrm{~b}^{\mathrm{A}}$ & $6,80 \mathrm{a}^{\mathrm{A}}$ \\
\hline 98 & $1,80 \mathrm{~b}^{\mathrm{B}}$ & $6,60 \mathrm{a}^{\mathrm{A}}$ & $0,80 \mathrm{a}$ & $0,60 \mathrm{~b}^{\mathrm{B}}$ & $5,20 \mathrm{a}^{\mathrm{A}}$ & $16,80 \mathrm{a}^{\mathrm{A}}$ & $7,40 \mathrm{a}^{\mathrm{B}}$ \\
\hline S/SEC & - & - & $2,35 \mathrm{~A}$ & - & - & - & - \\
\hline $\mathrm{C} / \mathrm{SEC}$ & - & - & $1,10 \mathrm{~A}$ & - & - & - & - \\
\hline C.V. $(\%)$ & \multicolumn{2}{|c|}{25,17} & 47,59 & \multicolumn{2}{|c|}{32,91} & \multicolumn{2}{|c|}{24,64} \\
\hline
\end{tabular}

(1) Dias após a etiquetagem; etiquetagem das inflorescências em final de florescimento.

(2) Médias seguidas da mesma letra, minúscula para colheita e maiúscula para secagem, não diferem entre si, pelo teste de Tukey a $5 \%$.

Comparando os resultados dos testes de germinação das sementes frescas e sementes secas, quando sem escarificação (Tabela 4), nas quatro colheitas finais (77 a 98 DAE) verificaram-se diferenças para germinação, sementes mortas e sementes duras, com efeitos de interação. Nas sementes secas, os resultados foram semelhantes entre as quatro épocas, à exceção da germinação, enquanto nas sementes frescas ocorreram variações entre as épocas de colheita. Assim, nas sementes frescas foi possível ver, de forma evidente com a evolução da perda de água (Tabela 1), aumentos da germinação concomitantes à diminuição das sementes mortas, para na última colheita apresentar baixa germinação devido ao aumento das sementes duras com a secagem (Tabela 4). Dessa forma, as diferenças de germinação entre sementes frescas e sementes secas são justificadas pelas sementes mortas (77 DAE) e pelas sementes duras (98 DAE), em maior número nas sementes frescas (Tabela 4).

$\mathrm{Na}$ comparação dos resultados dos testes de germinação entre sementes frescas e secas, com escarificação (Tabela 5), tornou-se evidente que a secagem das sementes no interior dos frutos, mesmo estes destacados das plantas, antecipou a maturação das sementes imaturas, igualando os números de sementes germinadas, plântulas anormais e sementes mortas das quatro últimas colheitas (77 a 98 DAE); nas frescas houve gradiente dos 77 aos 98 DAE, com aumentos das sementes germinadas e diminuição das sementes mortas, enquanto as plântulas anormais diminuíram a partir dos 84 DAE, mostrando a evolução da maturação e da secagem das sementes frescas no decorrer dessas colheitas. As diferenças de germinação entre sementes frescas e sementes secas nas três colheitas que antecederam a do início de dispersão dos frutos (98 DAE) foram proporcionadas pelo maior número de sementes mortas e, /ou, de plântulas anormais nas sementes frescas (Tabela 4), talvez pelo prejuízo ocasionado nestas pela escarificação das sementes com maior teor de água. Os resultados das sementes secas e frescas foram semelhantes na última colheita em todos os parâmetros avaliados no teste de germinação, indicando que a secagem das sementes nos frutos colhidos havia-se completado e em condições para sofrerem dispersão.

Esses resultados indicam a possibilidade de se colher em frutos de canafístula até três semanas antes do início da dispersão, desde que a seguir sofram secagem em ambiente à sombra para, então, se proceder à extração das sementes secas, que passam a apresentar comportamento similar ao das originadas dos frutos secos naturalmente na planta.

É interessante salientar que, entre as cinco plantas escolhidas para a colheita dos frutos, houve diferença de comportamento de suas sementes no decorrer das colheitas quanto à germinação, quando submetidas à escarificação, indicando desuniformidade de maturação entre elas, apesar da aparente homogeneidade de estádios de florescimento por ocasião da escolha das árvores. 
Tabela 5 - Médias de germinação, plântulas anormais, sementes mortas e sementes duras de canafístula obtidas para sementes frescas (S/SEC) e sementes secas nos frutos (C/SEC), com escarificação, originárias de diferentes épocas de colheita definidas em dias após a etiquetagem (DAE) $\left(n^{\circ}=20\right.$ sementes por repetição).

Table 5 - Means of germination, abnormal seedlings, dead seeds, and hard seeds of horsebush obtained for fresh seeds (without drying) and seeds dried inside the fruits (artificial drying), both with scarification, at different harvest times (days after labeling - DAL). ( $n^{o}=20$ seeds per replication).

\begin{tabular}{|c|c|c|c|c|c|c|c|}
\hline \multirow[t]{2}{*}{$\begin{array}{c}\text { Tratamentos } \\
\text { Colheita/Escarificação }\end{array}$} & \multicolumn{2}{|c|}{$\begin{array}{l}\text { Germinação } \\
\left(\mathrm{n}^{\circ}\right)\end{array}$} & \multicolumn{2}{|c|}{$\begin{array}{c}\text { Plântulas } \\
\text { Anormais }\left(\mathrm{n}^{\circ}\right)\end{array}$} & \multicolumn{2}{|c|}{$\begin{array}{c}\text { Sementes } \\
\text { Mortas }\left(\mathrm{n}^{\circ}\right)\end{array}$} & \multirow[t]{2}{*}{$\begin{array}{r}\text { Sementes } \\
\text { Duras }\left(n^{\circ}\right)\end{array}$} \\
\hline & $\mathrm{S} / \mathrm{ESC}$ & $\mathrm{C} / \mathrm{ESC}$ & $\mathrm{S} / \mathrm{ESC}$ & $\mathrm{C} / \mathrm{ESC}$ & S/ESC & C/ESC & \\
\hline \multicolumn{8}{|l|}{$(\mathrm{DAE})^{1}$} \\
\hline 77 & $0,40 \mathrm{c}^{\mathrm{B}(2)}$ & $17,00 \mathrm{a}^{\mathrm{A}}$ & $0,80 \mathrm{c}^{\mathrm{A}}$ & $0,80 \mathrm{a}^{\mathrm{A}}$ & $18,80 \mathrm{a}^{\mathrm{A}}$ & $1,00 \mathrm{a}^{\mathrm{B}}$ & $0,60 \mathrm{a}$ \\
\hline 84 & $9,80 \mathrm{~b}^{\mathrm{B}}$ & $17,80 \mathrm{a}^{\mathrm{A}}$ & $5,20 \mathrm{a}^{\mathrm{A}}$ & $0,60 \mathrm{a}^{\mathrm{B}}$ & $2,20 \mathrm{~b}^{\mathrm{A}}$ & $0,60 \mathrm{a}^{\mathrm{A}}$ & $1,90 \mathrm{a}$ \\
\hline 91 & $13,00 \mathrm{~b}^{\mathrm{B}}$ & $18,00 \mathrm{a}^{\mathrm{A}}$ & $3,20 \mathrm{ab}^{\mathrm{A}}$ & $0,20 \mathrm{a}^{\mathrm{B}}$ & $3,20 b^{A}$ & $0,80 a^{\mathrm{B}}$ & $0,80 \mathrm{a}$ \\
\hline 98 & $17,80 \mathrm{a}^{\mathrm{A}}$ & $17,40 \mathrm{a}^{\mathrm{A}}$ & $1,40 \mathrm{bc}^{\mathrm{A}}$ & $0,40 \mathrm{a}^{\mathrm{A}}$ & $0,60 \mathrm{~b}^{\mathrm{A}}$ & $1,00 \mathrm{a}^{\mathrm{A}}$ & $0,70 \mathrm{a}$ \\
\hline S/SEC & - & - & - & - & - & - & $0,90 \mathrm{~A}$ \\
\hline C/SEC & - & - & - & - & - & - & $1,10 \mathrm{~A}$ \\
\hline C.V. (\%) & \multicolumn{2}{|c|}{10,97} & \multicolumn{2}{|c|}{26,88} & \multicolumn{2}{|c|}{28,63} & 46,95 \\
\hline
\end{tabular}

(1) Dias após a etiquetagem; etiquetagem das inflorescências em final de florescimento.

(2) Médias seguidas da mesma letra, minúscula para colheita e maiúscula para secagem, não diferem entre si, pelo teste de Tukey a $5 \%$.

\section{CONCLUSÕES}

A maior capacidade germinativa das sementes de canafístula é atingida após a ocorrência do máximo acúmulo de massa.

As sementes de canafístula apresentam o máximo potencial de germinação no início do processo de dispersão, quando predominam sementes duras.

A maturação, a germinação e a instalação da dormência na semente imatura de canafístula são antecipadas com a sua secagem no fruto separado da planta-mãe.

\section{REFERÊNCIAS}

BASKIN, C. C.; BASKIN, J. M. Seeds: ecology, biogeography, and evolution of dormancy and germination. San Diego: Academic Press, 1998. 666p.

BIANCHETTI, A.; RAMOS, A. Comparação de tratamentos para superar a dormência de sementes de canafístula (Peltophorum dubium (Spreng.) Taub.). Boletim de Pesquisa Florestal, n.4, p.91-99, 1982.

BRASIL. Ministério da Agricultura e Reforma Agrária. Regras para análise de sementes. Brasília: SNDA/DNDV/CLV, 1992.365p.
CARDOSO, V. J. M. Dormência: estabelecimento do processo. In: FERREIRA, A.G.; BORGHETTI, F. Germinação: do básico ao aplicado. Porto Alegre: Artmed, 2004. p.95-108.

CHAVES, R.; KAGEYAMA, P. Y. Determinação do início da dormência no desenvolvimento das sementes de Delonix regia (Raf.) - "flamboyant". Circular Técnica IPEF, n.117, p.1-4, 1980.

DONADIO, N. M. M.; DEMATTÊ, M. E. S. P. Morfologia de frutos, sementes e plântulas de canafístula (Peltophorum dubium (Spreng.) Taub.) e jacarandá-da-bahia (Dalbergia nigra (Vell.) Fr.All. ex Benth.). FABACEAE. Revista Brasileira de Sementes, v.22, n.1, p.64-73, 2000.

DURIGAN, G. et al. Sementes e mudas de árvores tropicais. São Paulo: Páginas e Letras, 1997. 65p.

EDWARDS, D. G. W. Maturity and quality of tree seeds - a state-of-the-art review. Seed Science \& Tecnology, v.8, n.4, p.625-657, 1980.

FIGLIOLIA, M. B. Colheita de sementes. IF Série Registros, n.14, p.1-12, 1995.

GOMES, F. P. Curso de estatística experimental. Piracicaba: Nobel, 2000. 477p.

R. Árvore, Viçosa-MG, v.34, n.1, p.49-56, 2010 
FIGLIOLIA, M. B.; SILVA, A. Germinação de sementes beneficiadas e não beneficiadas de Peltophorum dubium (Spreng.) Taubert. em laboratório e viveiro sob tratamentos prégerminativos. Silvicultura em São Paulo, v.16 A, p.908-916, 1982. (Numero Especial)

KERMODE, A. R. Regulatory mechanisms in the transition from seed development to germination: interactions between the embryo and the seed development. In: KIGEL, J.; GALILI, G. Seed development and germination. New York: Marcel Dekker, 1995. p. 273-332.

LORENZI, H. Árvores brasileiras: manual de identificação e cultivo de plantas arbóreas nativas do Brasil. Nova Odessa: Plantarum, 1992. 352p.

\section{MARCHIORI, J. N. C. Dendrologia das} angiospermas: leguminosas. Santa Maria: Universidade Federal de Santa Maria, 1997. 200p.

NAKAGAWA, J.; CAVARIANI, C.; ZUCARELI, C. Maturação, formas de secagem e qualidade fisiológica de sementes de mucuna-preta.

Revista Brasileira de Sementes, v.27, n.1, p.45-53, 2005.

OLIVEIRA, E. C.; PIÑA-RODRIGUES, F. C. M.; FIGLIOLIA, M. B. Proposta para a padronização de metodologia em análise de sementes florestais. Revista Brasileira de Sementes, v.11, n. 1/3, p. 1-42, 1989.
OLIVEIRA, L. M.; DAVIDE, A. C.; CARVALHO, M. L. M. Avaliação de métodos para quebra de dormência e para desinfestação de sementes de canafístula (Peltophorum dubium (Spreng.) Taub.). Revista Árvore, v.27, n.5, p.597603, 2003.

OLIVEIRA, L. M.; DAVIDE, A. C.; CARVALHO, M. L. M. Teste de germinação de sementes de Peltophorum dubium (Sprengel) Taubert-

Fabaceae. Floresta, v. 38, n. 3, p. 545-551, 2008.

PEREZ, S. C. J. G. A.; FANTI, S. C.; CASALI, C. A. Dormancy break and light quality effects on seed germination of Peltophorum dubium Taub. Revista Árvore, v. 23, n. 2, p. 131-137, 1999.

PIÑA-RODRIGUES, F. C. M.; AGUIAR, I. B. Maturação e dispersão de sementes. In: AGUIAR, I. B.; PIÑA-RODRIGUES, F. C. M.; FIGLIOLIA, M. B. Sementes florestais tropicais. Brasília: ABRATES, 1993.p.215-274.

SANTOS, T. O.; MORAES, T. G. O.; MATOS, V. P. Escarificação mecânica em sementes de chichá (Sterculia foetida L.). Revista Árvore, v.28, n.1, p.1-6, 2004.

SIDHU, S. S.; CAVERS, P. B. Maturitydormancy relatioships in attached and detached seeds of Medicago lupulina L. (Black medick). Botanical Gazette, v.138, n.2, p.174-182, 1977. 